\title{
Innovative application of quality management method in LE engineering construction process
}

\author{
Mao Wenbo \\ Yunnan College of Business Management, Yunnan, China, 650304
}

Keywords: quality management; LE engineering; application

\begin{abstract}
As our country's pillar industry and strategic industry, the healthy development of the building industry directly affects China's national economy. From the perspective of building practice, China's construction enterprises carry out engineering management based on the traditional "person governance" management method, which makes the quality of construction engineering always at a low level. Even in the LE project, the "tofu" building has appeared. Thus it puts forward higher requirements to building construction enterprises, urging them to study scientific quality management theories and methods and put them into use, to improve the quality of construction management level and then build more high-quality buildings. This paper briefly analyzes the present situation of LE construction quality management, and mainly expounds the application of quality management methods in LE engineering construction, so that LE engineering construction enterprises can improve quality management efficiency and achieve sustainable and healthy development of construction engineering industry.
\end{abstract}

\section{Introduction}

Quality is the lifeline of an enterprise and the basic guarantee for the sustainable development and transformation of the national economy. If the quality of a company's products is difficult to guarantee, it will directly restrict the growth of the company and even affect the survival of the company. In the construction of LE engineering, the construction quality will also have an adverse effect on the safety of construction and operation, and it will also threaten the life and property safety of LE engineering users. Therefore, it is of great significance to carry out the application research of LE engineering construction quality management methods and to explore ways to improve the quality of LE engineering from three aspects: enterprise, country and user. From the perspective of construction companies, it can promote construction enterprises to improve management levels, improve the production efficiency of industrial products, and enhance the competitiveness of enterprises. Standing on the national standpoint, as the pillar industry of the national economy, this can stimulate the development of the upstream and downstream industries, promote the transformation and upgrading of the national economy, and safeguard the healthy development of the national economy. In addition, the improvement of the quality and performance of LE engineering construction can fully guarantee the safety and use requirements of LE engineering users, and make LE project of people's confidence. Therefore, it is of far-reaching and extensive significance to study the application of LE project construction quality management 
method ${ }^{[1]}$.

\section{The current situation of LE construction quality management}

The most important content of LE engineering quality management is the quality management of engineering. The quality of its implementation will directly affect the LE project to a large extent. For construction companies, the quality of construction engineering is a concentrated expression of corporate management level, comprehensive competitiveness and technical level. Nowadays, the competition in the construction industry is becoming more and more fierce. Many construction companies face fierce market competition. In order to maximize the pursuit of economic benefits, they largely ignore the quality management system of construction projects. The quality management measures adopted in the construction of the project are relatively backward, and the planning, control and summary work of the construction project are not completed. In addition, the overall and effective dynamic quality management of the LE project has not been implemented ${ }^{[2]}$.

The Deming (PDCA) Cycle
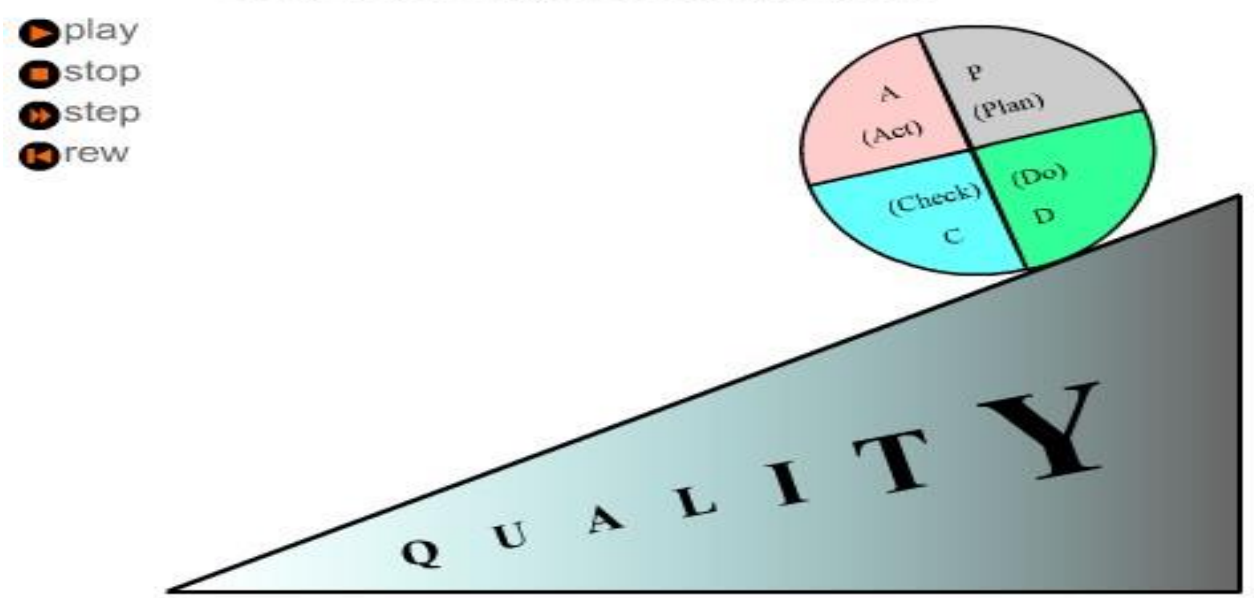

Figure 1: Quality management of well-known colleges and universities

After summarizing and analyzing, it can be concluded that there are mainly the following problems in the quality management of LE products in our country: First, the quality awareness of enterprise engineering quality management staff is relatively poor, and the project quality management is not paid enough attention. The construction unit has not established scientific and effective quality management training mechanism. Secondly, the LE project quality supervision and management system has not been perfected, so it is difficult to provide effective protection for LE projects in terms of quality. Thirdly, the fierce market competition in the construction industry further leads to a lot of non-standard behaviors in the market, such as the non-standard behaviors of the construction unit and the design unit during LE engineering construction, which has a direct impact on the quality of LE engineering management to a large extent. Fourthly, at present, there is no perfect quality management system in the LE project, which is difficult to adapt to the quality management needs in modern engineering construction ${ }^{[1]}$.

\section{Application of Quality Management in LE Engineering Construction}

The construction quality of the LE project can only achieve the desired effect, which can ultimately improve its application safety and durability. Quality management plays an important role in LE engineering construction. It is mainly used in safety control aspects of LE engineering, 
engineering cost control, engineering quality control and engineering schedule control. The following is a specific analysis:

\subsection{Application in safety control}

The application of quality management in LE engineering construction will greatly improve the safety awareness of construction workers and management staff, and further make the construction specifications and standard specifications in LE engineering more detailed. At the same time, it can improve the technology in the construction of LE engineering, further improve the quality and safety supervision mechanism of the project, and continuously strengthen the safety control of LE engineering.

\subsection{Application in engineering cost control}

Cost control is an important part of the management of LE projects. In the process of LE engineering construction, quality management will effectively control the number of staff to a large extent, avoiding unnecessary labor costs. In this way, the efficiency of construction can be improved in synchronization with economic benefits, and the procurement target of raw materials in LE engineering can be better realized. At the same time, quality management can also reasonably improve the working efficiency of construction machinery and equipment, further reduce the construction cost of construction units, and maximize economic benefits ${ }^{[3]}$.

\subsection{Application in engineering quality control}

One of the most important work objectives and work contents in the LE project is the quality control of the project, and the staged quality control in the LE project construction is the focus of the overall effective quality control of the LE project. The application of quality management in LE engineering can improve the construction quality of LE engineering to a large extent, and can manage and control various factors of engineering quality. For example, in LE engineering quality management, the equipment and construction materials required to be constructed must comply with relevant requirements and specifications, and must have a complete set of technical specifications, product certification and other certificates. Under the quality management of LE engineering, the quality assurance department and organization design will be more complete and perfect, and the overall layout of the construction site will be more orderly. Under the quality management, the safety measures and construction techniques adopted during the construction process are also more targeted and time-sensitive ${ }^{[3]}$.

\subsection{Application in engineering schedule control}

One of the most important goals of LE engineering construction is the progress control of the project. In the process of LE engineering construction, the quality management adopted can not only maintain a good market economic order of the construction industry, but also improve the economic benefits of the construction unit to a large extent. Under the quality management of the LE project, the construction progress will be more scientific, the construction method will be more reasonable, and the connection and cooperation of each type of work will be more tight during the construction process. Especially when doing the overall project schedule, quality management can more scientifically ensure the forward-looking and predictability of the project schedule, and further make the project schedule to meet the construction conditions to the greatest extent. In addition, the adoption of quality management in LE engineering is conducive to the timely delivery of physical 
resources, human resources and capital of construction units, as well as the adjustment and resolution of relevant problems in the first time, so as to avoid hindering the progress of project construction $^{[2]}$.
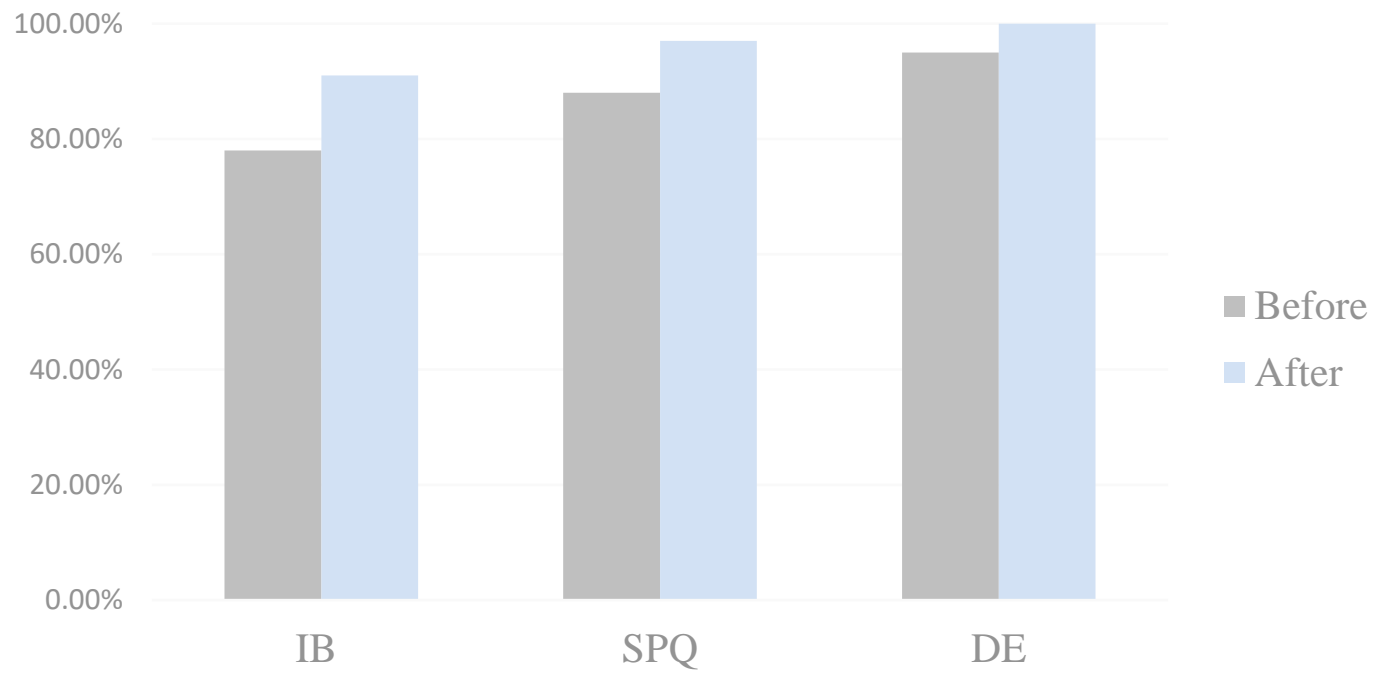

Figure 2: Comparison of quality performance of parts before and after quality optimization control in LE construction engineering

\section{Conclusions}

In the process of LE engineering construction, the adoption of quality management will greatly enhance the market competitiveness of enterprises, which can be developed and survive in the fierce market competition. At the same time, it can effectively promote the construction unit to establish a modern management system and constantly improve the overall quality of the LE project. Therefore, it is necessary to strictly implement the concept of quality management in the LE engineering construction. We need to standardize and program the actual work during the construction, so that the construction quality level of the project can be constantly improved, and further promote the social and economic benefits of the construction unit.

\section{References}

[1] Gao Shan. Application of Total Quality Management in Construction Engineering Quality Management[J]. City Architecture, 2017(9):121-121.

[2] Lai Zhuoli. Construction Safety Management and Construction Quality Management of Construction Engineering[J]. Building Materials Technology and Application, 2010(7): 47-48.

[3] Yan Lei. Research on Construction Quality Management of Building Construction Engineering [D]. Jilin University, 2015. 